\title{
Article
}

\section{Team Research at the Biology-Mathematics Interface: Project Management Perspectives}

\author{
John G. Milton, ${ }^{*}$ Ami E. Radunskaya, ${ }^{\dagger}$ Arthur H. Lee, ${ }^{\ddagger}$ Lisette G. de Pillis, ${ }^{\S}$ \\ and Diana F. Bartlett ${ }^{\mathbb{I}}$
}

The Claremont Colleges: *Joint Science Department, ${ }^{\dagger}$ Pomona College, ${ }^{\ddagger}$ Claremont McKenna College, ${ }^{\S}$ Harvey Mudd College, and ${ }^{\mathbb{I I}}$ Keck Graduate Institute of Applied Life Sciences, Claremont, CA 91711

Submitted March 15, 2010; Revised June 11, 2010; Accepted June 11, 2010

Monitoring Editor: John Jungck

\begin{abstract}
The success of interdisciplinary research teams depends largely upon skills related to team performance. We evaluated student and team performance for undergraduate biology and mathematics students who participated in summer research projects conducted in off-campus laboratories. The student teams were composed of a student with a mathematics background and an experimentally oriented biology student. The team mentors typically ranked the students' performance very good to excellent over a range of attributes that included creativity and ability to conduct independent research. However, the research teams experienced problems meeting prespecified deadlines due to poor time and project management skills. Because time and project management skills can be readily taught and moreover typically reflect good research practices, simple modifications should be made to undergraduate curricula so that the promise of initiatives, such as MATH-BIO 2010, can be implemented.
\end{abstract}

\section{INTRODUCTION}

Despite two seminal reports on the need for educational reform in biology at the undergraduate level (National Research Council, 2003; Steen, 2005), most undergraduate students continue to view mathematics and biology as "the two solitudes: together, but separate; alone, but together" (MacLennan, 1945). Blaming the faculty or the students is unfair. After all, how were these educational changes to be implemented? More to the point, how was the combination of mathematics and biology to be translated into technology, jobs, and more?

What is the educational challenge? Simply put, undergraduate biology and mathematics students must be prepared to function within interdisciplinary teams. The rapid pace of science and technology makes it impossible for an individual to possess the entire skill set to complete largescale projects: holes in skill sets translate into missed oppor-

DOI: $10.1187 /$ cbe.10-03-0021

Address correspondence to: John G. Milton (jmilton@jsd.claremont.edu).

(C) 2010 J. G. Milton et al. CBE-Life Sciences Education (C) 2010 The American Society for Cell Biology. This article is distributed by The American Society for Cell Biology under license from the author(s). It is available to the public under an AttributionNoncommercial-Share Alike 3.0 Unported Creative Commons License (http://creativecommons.org/licenses/by-nc-sa/3.0). tunities. Whereas educators have traditionally selected for students who are creative, independent thinkers, rather than collaborative team players, the dramatic success of large teams of investigators to solve major problems, such as the human genome project (Collins et al., 2003), is undeniable. It is not surprising that employers are increasingly focused on skill sets not emphasized in traditional educational institutions, namely, productive team work, critical thinking, problem solving, project management, and effective communication-the very aspects of an education that are typically neglected.

Interdisciplinary teams require some form of project management to be successful (Kraut et al., 1987; Hensey, 2001; Portny and Austin, 2002; Collins et al., 2003; Nokes, 2007): What are the goals and deadlines, what are the steps needed to accomplish the goals, how are the different parts of the project to be coordinated, and how are problems to be identified, corrected and even anticipated? Although most educators tend to identify these questions solely to industrial, large-scale type research projects, the very same problems arise in the setting of a liberal arts college. For example, biology professors typically supervise multiple, distinct senior thesis projects: Could this process be improved by utilizing project management skills so that the professor's time would be effectively distributed to meet the needs of his or her students?

To meet these challenges, we have developed an undergraduate research program to prepare biology and mathe- 
matics students to work effectively in interdisciplinary teams. This project, funded by the National Science Foundation (NSF), is named Research Experiences at the BiologyMathematics Interface (REBMI), has an organizational committee that includes biomathematicians (J.G.M., A.E.R., L.G.dP.), a computer scientist (A.H.L.), and a certified project management specialist (D.F.B.). The project is divided into two parts, each lasting $2 \mathrm{yr}$. The goal of the baseline phase is to identify factors that adversely affected the ability of the research team to deliver a product, specifically a poster and a submission-ready manuscript, by prespecified deadlines. The goal of the intervention phase is to introduce changes to REBMI that addressed issues in the baseline phase and determine their effect.

Here, we present our results for the baseline phase that has just been completed. Our observations suggest that interventions that expose students to basic principles of time and project management (e.g., goal setting, work schedule, team member roles, problem solving) will be necessary for students to function effectively in the modern interdisciplinary workplace.

\section{REBMI}

The goal of the REBMI program is to enable students to develop skill sets necessary to work in interdisciplinary teams that function at the interface between biology and mathematics. REBMI provides courses in biomathematics, interdisciplinary seminars and workshops, summer team research projects, and a variety of capstone experiences (see rebmi.jsd.claremont.edu). In total, 125 students participated in at least one of these activities during the past $2 \mathrm{yr}$ of this project. This communication focuses on the 25 students who chose to participate in the summer team research projects.

Biology and mathematics students were recruited in their sophomore year and were required to obtain introductory training in mathematics through differential equations and to have a scientific computer programming experience (e.g., MATLAB, Python). They obtained this training either as part of their college core (Harvey Mudd College [HMC]) or through a specially designed REBMI course in biomathematics (click on COURSES at rebmi.jsd.claremont.edu), or by taking existing courses in the major (Differential Equations and Modeling or Mathematical Modeling at Pomona College). Many of these students also had participated in a scientific Python (SciPy) workshop: a 2-day intensive workshop on scientific computing in Python that introduces students to portable open source software, including a wide range of tools for doing statistical and data analysis, numerical modeling, and visualization. Most participated in the REBMI team summer research project in the summer between their junior and senior years. Students were assigned to a team composed of a mathematically oriented student and a benchtop research oriented student, and they are expected to obtain an implementable solution in a novel problem-solving setting. By the term novel problem-solving setting, we mean topics that were not explicitly covered in their course work or related specifically to their previous research experience. Each student research team was given two deadlines: 1) presentation of a poster at a postsummer REBMI event and 2) completion of a submission-ready manuscript before graduation.
One of the philosophies of REBMI, motivated by experience of athletic coaches to enhance game performance using variable practice (Landin et al., 1993; Fairweather, 2003), is to expose students to a variety of problem-solving experiences at the interface between biology and mathematics. Thus, we encourage students to undertake research projects in their senior year that were not necessarily directly related to their REBMI research project. This is accomplished by leveraging three existing capstone experiences provided for all science and mathematics students at the Claremont Colleges, namely, a senior thesis, a Harvey Mudd College (HMC) global clinic, or a Keck Graduate Institute in Applied Life Sciences (KGI) Team Master's Project. The latter two experiences are industry-sponsored projects that involve interdisciplinary teams of students and Claremont faculty who work with scientists at the sponsoring company to produce a specific set of deliverables by a set deadline. The problems provided by the sponsoring companies are the untried and open-ended questions that stimulate creative thinking.

\section{The Claremont Colleges}

The Claremont University Consortium is a large research and educational environment consisting of five undergraduate liberal arts colleges, KGI, and the Claremont Graduate University. Together, these institutions have 66 mathematics and $>100$ science faculty. The Claremont Colleges have a combined student body of nearly 6500 . Each of the colleges is a discrete entity with its own distinct focus: Claremont McKenna College emphasizes government and economics; Pitzer College stresses social justice; Scripps College highlights the humanities, fine arts and science for women; HMC stresses engineering; and Pomona College is a broadly based liberal arts college. The Joint Science Department (JSD) was established in 1964 and is the science department for three of the five Claremont Colleges: Claremont McKenna, Pitzer, and Scripps colleges. The other two colleges, Pomona and Harvey Mudd, maintain standalone science departments.

\section{MATERIALS AND METHODS}

\section{Student Recruitment}

The REBMI program was funded by the NSF in fall 2006. This communication focuses on the cohort of 25 students that elected to participate in REBMI-funded team research projects that began in summer 2008. Students were recruited into REBMI by using recruitment seminars, faculty referrals, and referrals by other REBMI students with the emphasis on identifying students who enjoyed solving problems. The interdisciplinary and quantitative nature of this team-based initiative prompted students to self-select. All students were highly motivated toward participating in a team interdisciplinary research project, and no students who wished to participate were denied this opportunity on the basis of their academic performance (the number of student research stipends for REBMI teams represented $\approx 10 \%$ of the total number of summer research stipends available to students at the Claremont Colleges).

Grade point averages of the participating students ranged from 3.3 to 4.0. The first two summer team research projects 
constitute the preintervention phase of the study and have been completed: 15 students (eight teams) in summer 2008 and 10 students (five teams) in summer 2009. The second 2 years are the intervention phase of the study: 20 students (10 teams) participated in summer 2010 and 10 students (five teams) will participate in summer 2011. This study was approved by the Institutional Review Board at Claremont McKenna College in accordance with the currently available U.S. Public Health Service Guidelines. All participants provided written informed consent for all research testing.

\section{Mentor Recruitment}

We recruited team mentors from major research universities across the United States and Canada. Each mentor, or pair of mentors, is provided with a team of two REBMI students: one mathematically/computationally oriented student (MATH) plus an experimentally oriented biology student (BIO). (The first year there were three one-student teams, two or three of these students participated in a team at the host institution; data collected from the remaining student is included in the student performance assessments but not in the team performance assessment.)

Our criteria for selecting host laboratories and mentors were that the mentors 1) expressed interest in working with undergraduates; 2) had active laboratories; and, if possible, 3) had hosted biomathematics summer school programs. The host institutions were Cal Lutheran University, McGill University, University of British Columbia, University of California, San Francisco, University of Kansas, University of Ottawa, University of Southern California, Washington State University, and Washington University in St. Louis. The titles of the posters presented by the REBMI teams at the summer's end poster session for the first 2 yr of the REBMI project are given in Table 1.

The guidelines used in constructing the teams were: 1) the combined abilities of the team members are well suited to the requirements of the research project and 2) that neither student had specifically worked on the topic of the mentors' research. To encourage students to think outside the box and to mimic a real-life problem-solving experience, the mathematics and the biology student were not permitted to choose either their project or their research partner. Students were notified in March of each year that they would be doing a summer research project and were given the name of the student partner and the mentors. They then contacted their partner, arranged a meeting, and together wrote a letter of introduction to the mentors. Their letter of introduction included an abbreviated biography that focused on those aspects of their background that were most relevant to their role (mathematician or biologist) on the team, e.g., courses in mathematics, biology lab course, and previous research experiences. To promote planning and organizational skills, students worked with their mentors and local housing offices to arrange their travel and accommodations and to negotiate dates when the research would be conducted. Typically, students did not know the exact nature of their project until they arrived in the mentors' labs; however, they were encouraged to visit the mentors' websites and review their papers. They were given two deadlines: presentation of a
Table 1. REBMI team projects for years 1 and 2

- Protein hopping simulations and the importance of subexposure behavior in protein-DNA interactions (Washington University in St. Louis)

- Computational modeling of gene expression and the effect of scaffold proteins (McGill University)

- Algorithms for seizure detection in electroencephalogram and electrocorticogram (University of Kansas Medical Center)

- Modeling infection dynamics of equine infectious anemia virus (Washington State University)

- Scalable optimization of adaptive scheduling in SWIFT for large parallel computation on grids (University of Chicago)

- Using genetic algorithms to explore motifs for efficient macromolecular assembly (McGill University)

- Evaluating the accuracy of computer navigation in perioperatively planned acetabular osteotomies (University of California, San Francisco)

- Human hand: the mechanical finger (University of Southern California)

- Effects of downhill running on body mechanics and kinetics; the correlation of postural sway to lower extremity maximal muscle strength (Cal Lutheran University) ${ }^{\mathrm{a}}$

- Survival and proliferation of chronic lymphocytic leukemia in lymphoid tissue (HMC)

- Modeling mammalian limb tactile sensation in a spinal like regulator (University of Southern California)

- Observing and modeling dynamics of the Min protein system (University of British Columbia)

- Infant bouncing paradigm (University of Ottawa)

- A comparison between visual and acoustical whisker localization techniques (University of Southern California)

${ }^{\mathrm{a}}$ Lab hosted an REBMI team both years.

poster at the end of the summer and a submission-ready manuscript by the beginning of the next summer.

\section{Evaluation}

At the end of the summer research experience, team mentors were asked to evaluate each team member by using a performance rubric (Table 2). This rubric is similar to the rubric that is currently used to evaluate students who participate in a Team Masters Project at KGI. A project management rubric (Table 3) was developed by a certified project management professional (D.F.B.) and used by the REBMI investigators (J.G.M., A.E.R., A.H.L., L.G.dP.) to score team performance. This scoring was based on written/verbal responses of the students and mentors, productivity of the team (e.g., abstracts,

Table 2. Evaluation rubric for team members

Score on scale: 5, excellent and 1, poor

Quality of work

Ability to communicate

Ability to provide leadership

Commitment to team and project

Respect shown for team members

Creativity

Reliability

Initiative 
Table 3. Evaluation rubric for team performance

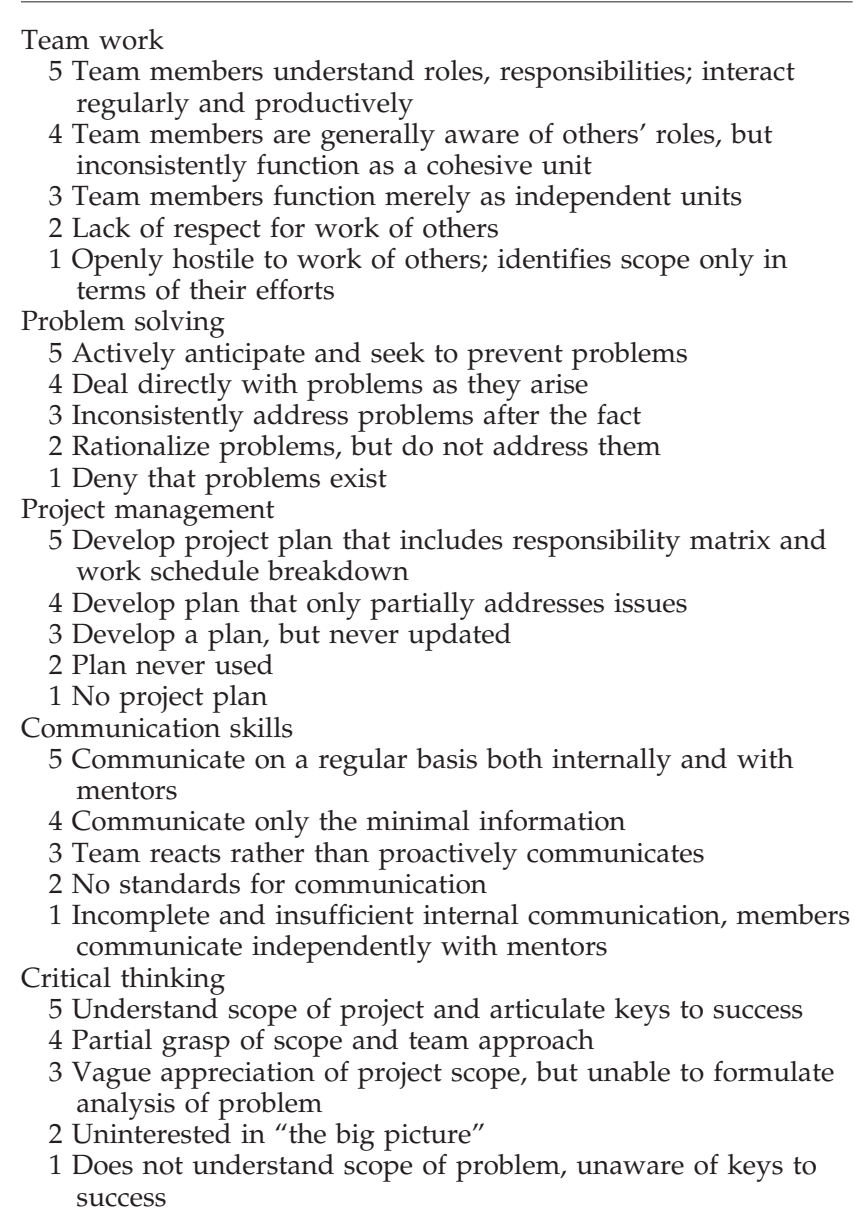

submitted manuscripts), and responses of students to a review of the students conducted in the early fall of the year the summer research was completed by a team of external reviewers selected from the biomathematics community.

\section{RESULTS}

Here, we report on outcomes for the 2-yr preintervention component of our study. Twenty-five (25) students completed an 8-wk team research experience at the interface between biology and mathematics. For 24 of 25 students, the research experience involved a team and was conducted off-campus.

\section{Student Performance}

Figure 1 summarizes the performance of the students as evaluated by their mentors by using the rubric shown in Table 2. Overall, individual student performance was at the very good to excellent level (mean scores were greater than 4 of 5). These observations are consistent with the fact that the Claremont Colleges are highly selective institutions: As a group they rank eighth nationally for student selectivity,

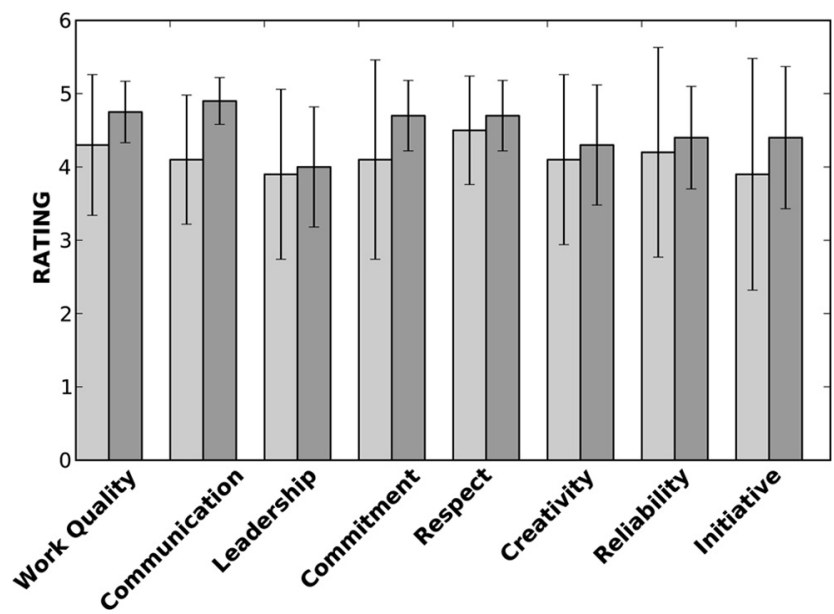

Figure 1. Student performance for the summer research projects conducted in 2008 (light gray) and 2009 (dark gray) by using the rubric given in Table 1. The height of the columns gives the mean score and the error is $\pm 1 \mathrm{SD}$.

with a mean SAT score of 1400 (science plus verbal) for the entering first-year class. The careers of this student cohort following the summer research experience emphasize that this student cohort continued to perform at a high level (Table 4). The high participation of students in a two-semester thesis (JSD, Pomona) or an industry-sponsored clinic (HMC) is typical for science and mathematics students at the Claremont Colleges. An encouraging outcome is that 12 students are in graduate school working on topics at the interface between biology and mathematics: applied mathematics and statistics (three), biochemistry (one), biomedical engineering (two), biomathematics (three), and computational science (three).

\section{Team Performance}

All teams produced a poster on time for the end of summer poster session. However, no team was able to produce a submission-ready manuscript within $1 \mathrm{yr}$, even though students were encouraged and given opportunities to do so (e.g., academic credit was possible through independent study). Common problems included not ordering critically

Table 4. Outcomes of team members

\begin{tabular}{lcc}
\hline \multicolumn{1}{c}{ Outcome } & Year $1^{\mathrm{a}}$ & Year 2 \\
\hline Senior thesis & 8 & 3 \\
HMC clinic & 5 & 1 \\
Team Masters Project & 1 & 2 \\
Graduate school & 8 & 4 \\
Medical profession & 2 & 2 \\
Business & 1 & 1 \\
Claremont Colleges & 0 & $2^{\mathrm{b}}$ \\
Lost to follow-up & 3 & 0
\end{tabular}

${ }^{a}$ One student deceased.

${ }^{b}$ Two students did the REBMI research experience between their sophomore and junior year. 


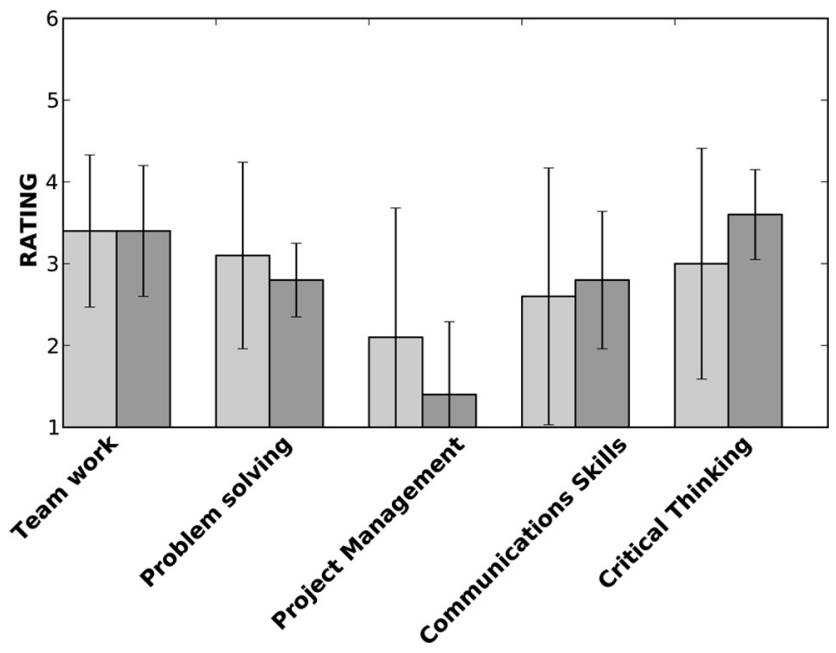

Figure 2. Team performance for the summer research projects conducted in 2008 (light gray) and 2009 (dark gray) by using the rubric given in Table 2 . The height of the columns gives the mean score and the error is $\pm 1 \mathrm{SD}$.

important reagents until they ran out, not asking for help early, not completing time-consuming but necessary tasks on schedule such as calibrations and simulations, lack of crosstraining between team members, and poor division of labor. The team performance (students plus mentors) as assessed by us by using the rubric in Table 3 is shown in Figure 2. Overall team performance was poorer than the students' individual performances (compare Figures 1 and 2).

\section{DISCUSSION}

Our observations underscore the disconnect that exists between the preparation of students in the classroom and the expectations of the research workplace. Whereas the operational goal of education is to assess the strengths and weaknesses of an individual, the performance of the individual in the workplace is all about how their team performs, e.g., was an implementable solution delivered by a specified deadline? We conjecture that simple modifications to undergraduate curricula to expose biologists to more mathematics, and vice versa, are unlikely to reap benefits in the workplace unless basic issues of team performance also are addressed.

We assessed the ability of the research team (students plus mentors) to deliver products, namely, a poster and a submission-ready manuscript, by prespecified deadlines. We observed that the research teams were able to meet the end of summer poster deadline but were unable to meet the manuscript deadline. It is important to note that although the length of time available to meet these deadlines was short (1 yr), the quality of the research itself did not seem to be the sole limiting factor. Indeed, eight of 13 of the team mentors believed that the research was of publishable quality, and this sentiment was echoed by the external reviewers at the end of summer poster session. The results in Figure 2 argue that poor project and time management are important contributing factors. It is quite likely that both mentors and students were equally at fault. Student teams did not typi- cally have a work plan with definable goals and deadlines, a clear delegation of responsibilities, a proactive problemsolving mechanism, and an understanding of different aspects of the study. Presumably the impact of these inefficiencies increased during the school year as other activities (e.g., course work, sports, social) are incorporated into an already dysfunctional project plan.

More traditional evaluations of educational initiatives focus on issues related to the quality of the experience: Did the student learn something and, perhaps more importantly, did the student become enthusiastic and inspired for scientific research? Certainly from these perspectives our REBMI initiative was a success (Table 4). Student evaluations of their own experiences were not statistically different from those provided by the mentor in Figure 1 (data not shown).

However, the important insight provided by REBMI is that students and perhaps mentors do not have the basic skills required to deliver a product by a specified deadline. The importance of this skill to a successful research career is self-evident (Clemente, 1973; Buchmueller et al., 1999; Williamson and Cable, 2003; Dorsey et al., 2006). In academic research failure to meet deadlines translates into lost opportunities: no presentations at scientific meetings, no grant support due to poor publication records, careers off track due to unnecessarily prolonged times to defense of graduate thesis. In industrial research, failure to meet deadlines often translates into loss of employment. The need for teaching basic time and project management skills is often overlooked. Time and project management skills can be readily taught and learned. Moreover, it should be possible to incorporate these skills into curricula, even at large educational institutions.

What is the relative role played by the length of time on a research project versus poor time management on the delivery of a publication by a specific date? A common misconception is to equate increasing team performance with the multitasking abilities of team members. Multitasking, i.e., the performance of two or more tasks concurrently by an individual, typically produces a decrease in performance (Milton et al., 2007, 2008; Klingberg, 2009), although exceptions occur (Milton et al., 2008). Modest improvements in an individual's ability to multitask can be achieved through training and experience (Dux et al., 2009); however, these improvements in performance are much smaller than the larger increases in team performance expected from parallel processing due to effective division of labor between team members. Thus, we suggest that poor time management may play a larger role in slowing down research than is generally realized. To test this hypothesis our intervention, introduced with this year's student-mentor cohort, is to provide both students and mentors with training in project management and team-based research before the research project is undertaken. A classroom kickoff outlining the key project management elements related to research projects was given to students and mentors at the end of the spring semester. This session focused on issues related to scheduling (e.g., start at the end and work backward), anticipating problems (e.g., equipment doesn't always function properly, people forget dates), and having a plan B. Teams prepare a scope project statement within $3 \mathrm{wk}$ of project onset, submit a finalized version by $4 \mathrm{wk}$, and keep a diary of the nature of deviations from the plan that arose and how these were 
resolved. Online preparation includes scope statement definition, problem solving, conflict management, and project plan updating. A classroom session in the fall provides an opportunity for teams and mentors to share their experiences and to modify preparation sessions for the coming year. Our hypothesis is that project management training will be reflected by timely submission of a manuscript for publication.

An essential first step for evaluating the impact of an educational intervention is establishing a preintervention baseline. We established our preintervention baseline by making use of external reviews obtained by sending our student team to off-campus laboratories. We believe that this strategy is the most effective and efficient way to determine how well our students have been prepared for research in a graduate school setting. Moreover, R1 universities have the resources, such as graduate students and postdoctoral fellows, to readily absorb a student research team into their ongoing activities. We leveraged our long standing in the biomathematical community to place our student teams. The advantage for the host laboratories was that they obtained an "extra pair of hands" at no cost to help their research efforts while also being afforded opportunities to assess, and possibly attract, future graduate students to their school. The advantage to our institutional programs was that we were able to quickly identify possible deficiencies in our educational programs that needed to be addressed, e.g., the need for better computer programming skills (MATLAB, Python) and hands-on experience for constructing laboratory equipment for novel experimental paradigms, e.g., basic machine, glass blowing, and electronic shop skills. Moreover, faculty researchers at our colleges were able to use the teams to help establish collaborations with host laboratories and students gained a sense of confidence and ownership for their research projects. Overall our observations suggest that an exchange of students between institutions at the laboratory level might be a mutually beneficial way to strengthen the impact of existing federally funded Research Experience for Undergraduate programs.

Recent research indicates that the neuroanatomy of individual and group performance is different. Whereas expert individual performance is related to focus on relevant details (posterior cingulate regions) and activation of the specific cortical regions required to complete the task (Milton et al., 2007), effective team work is based on trust and hence is mediated by the neuropeptide oxytocin and modulated by the neural systems involved in fear processing (amygdala and midbrain regions) and behavioral adaptations to feedback information (dorsal striatum) (Baumgartner et al., 2008). Thus, neither intuition nor experience necessarily provides the most accurate or appropriate pathways when attempting to design educational programs that enhance team performance. Indeed, many observations seem counterintuitive, such as the importance of variable practice for enhancement of skill (Landin et al., 1993), the roles played by attention and emotion on performance (Milton et al., 2007), and the role of distributed neural networks for decision making (Sanfey et al., 2003; Glimcher et al., 2009; Milton et al., 2010). The implications of these findings have already been translated into the development of new coaching strategies for athletes, i.e., how should practice be designed to enhance game performance (Fairweather, 2003) and decision-making strategies in the business world (Glimcher et al., 2009). In contrast there have been few applications to the training of young scientists and to the enhancement of the performance of interdisciplinary undergraduate research teams. However, project management skills can be readily taught and implemented and, moreover, reflect good research practices. By doing so we believe that the promise of projects, such as MATH-BIO 2010, can be realized.

\section{ACKNOWLEDGMENTS}

We thank T. Greg Dewey and Mario Martelli for helpful discussion during the early stages of this project. We thank John D. Hunter, Fernando Pérez, and Andrew D. Straw for developing the SciPy workshop. We thank the research mentors and external reviewers: Natalie Baddour, Jacques Bélair, Shane Burch, Sue Ann Campbell, Tansu Celikel, Eric Cytrynbaum, Angela Gallegos, Mohammed Diab, Mark G. Frei, James P. Keener, Michele Leblanc, Gerald Loeb, André Longtin, Seema Nanda, Ivan Osorio, Elissa Schwartz, Steve L. Small, Ana Solodkin, Heidi Sveistrup, Peter Swain, George Angelo Tsianos, Francicso Valero-Cuevas, and Yan Mei Wang. This research was supported by NSF grant UBM-0634592.

\section{REFERENCES}

Baumgartner, T., Heinrichs, M., Vonlanthen, A., Fischbacher, U., and Fehr, E. (2008). Oxytocin shapes the neural circuitry of trust and trust adaptation in humans. Neuron 58,639-650.

Buchmueller, T. C., Domintz, J., and Hansen, W. L. (1999). Graduate training and the early career productivity of Ph.D. economists. Econ. Educ. Rev. 14, 65-77.

Clemente, F. (1973). Early career determinants of research productivity. Am. J. Sociol. 79, 409-419.

Collins, F. S., Morgan, M., and Patrinos, A. (2003). The human genome projects: lessons from large-scale biology. Science 300, 286-290.

Dorsey, E. R., Rapheal, B. A., Balcer, L. J., and Galetta, S. L. (2006). Predictors of future publication record and academic rank in a cohort of neurology residents. Neurology 67, 1335-1337.

Dux, P. E., Tombu, M. N., Harrison, S., Rogers, B. P., Tong, F., and Marois, R. (2009). Training improves multitasking performance by increasing the speed of information processing in human prefrontal cortex. Neuron 63, 127-138.

Fairweather, M. (2003). Skill learning principles: implications for coaching practice. In: The Coaching Process: Principles and Practice for Sport, ed. N. Cross and J. Lyle, New York: ButterworthHeinemann, 113-129.

Glimcher, P. W., Camerer, C. F., Fehr E., and Poldrack, R. A. (eds.) (2009). Neuroeconomics: Decision-Making and the Brain, New York: Academic Press.

Hensey, M. (2001). Collective Excellence: Building Effective Teams, 2nd ed., Danvers, MA: ASCE Press.

Klingberg, T. (2009). The Overflowing Brain: Information Overload and the Limits of Working Memory, New York: Oxford University Press.

Kraut, R., Galegher, J., and Carmen, E. (1987). Relationships and tasks in scientific research collaborations. Hum. Comput. Interact. 3, 31-58.

Landin, D. K., Hebert, E. P., and Fairweather, M. (1993). The effects of variable practice on the performance of a basketball skill. Res. Q. Exer. Sport 64, 232-237.

MacLennan, H. (1945). Two Solitudes, Montreal, QC, Canada: McGill-Queen's University Press. 
Milton, J., Solodkin, A., Hlustik, P., and Small, S. L. (2007). The mind of expert motor performance is cool and focused. Neuroimage 35, 804-813.

Milton, J., Small, S. L., and Solodkin, A. (2008). Imaging motor imagery: methodological issues related to expertise. Methods 45, 336-341.

Milton, J., Naik, P., Chan, C., and Campbell, S. A. (2010). Indecision in decision-making neural networks. Math. Mol. Nat. Phenom 5, 125-145.

National Research Council (2003). BIO 2010: Transforming Undergraduate Education For Future Research Biologists, Washington, DC: National Academies Press.
Nokes, S. (2007). The Definitive Guide to Project Management, 2nd ed., London, United Kingdom: Financial Times/Prentice Hall.

Portny, S. E., and Austin, J. (2002). Project management for scientists. Science Careers (July 12).

Sanfey, A. G., Rilling, J. K., Aronson, J. A., Nystrom, L. E., and Cohen, J. D. (2003). The neural basis of economic decision-making in the ultimatum game. Science 300, 1755-1758.

Steen, L. A. (2005). Math \& Bio 2010, Linking Undergraduate Disciplines, Washington, DC: The Mathematical Association of America.

Williamson, I. O., and Cable, D. M. (2003). Predicting early career research productivity: the case of management faculty. J. Organ. Behav. 24, 25-44. 